\title{
An Ancient Christian Hymn with Musical Notation
}

\author{
Papyrus Oxyrhynchus 1786: Text and Commentary
}

[Ein früh-christlicher Hymnus mit Notation. Papyrus Oxyrhynchus 1786: Text und Kommentar.]

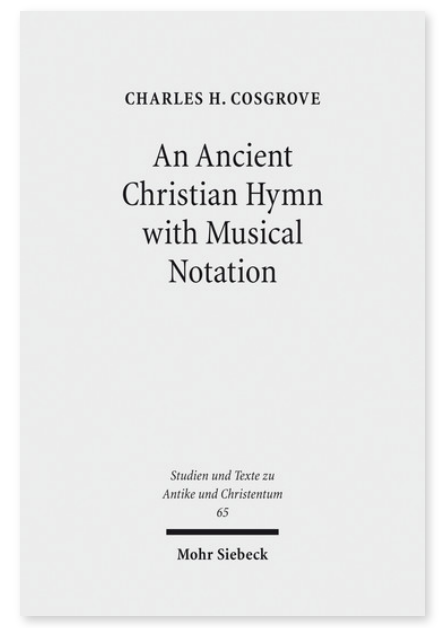

2011. XI, 232 Seiten. STAC 65

ISBN 978-3-16-151767-9

DOI 10.1628/978-3-16-151767-9

eBook PDF $89,00 €$

ISBN 978-3-16-150923-0

fadengeheftete Broschur 89,00€
Veröffentlicht auf Englisch.

Dieses Buch enthält eine umfassende Untersuchung des Papyrus Oxyrhynchus 1786, eines griechisch-christlichen Hymnus, der aus der zweiten Hälfte des dritten Jahrhunderts stammt und das früheste vorhandene Beispiel einer notenschriftlichen christlichen Melodie darstellt. Charles Cosgrove untersucht den Text und die Musik dieses Hymnus und stellt sie in den Kontext der griechischen literarischen (und hymnischen) Überlieferung, der altgriechischen Musik, der antiken christlichen Liturgie und Frömmigkeit und der gesellschaftlichen Umstände von Oxyrhynchus um 300 C.E. Der ausführliche Kommentar berührt die Fachgebiete der klassischen Philologen, der Kirchenhistoriker und der Musikhistoriker mit Interesse an griechischer Musik.

Charles H. Cosgrove Studied at University of Tubingen (Germany), Instituto Superior Evangelico De Estudios Teologicos (Buenos Aires, Argentina), Chicago-Kent College of Law (Chicago); M. Div. Bethel Theological Seminary; PhD Princeton Theological Seminary; Professor of New Testament at Northern Seminary, Lombard, Illinois (USA) from 1984-2011; Starting July, 2011: Professor of Early Christian Literature, Garrett-Evangelical Theological Seminary, Evanston, Illinois (USA).

Jetzt bestellen:

https://mohrsiebeck.com/buch/an-ancient-christian-hymn-with-musical-notation-9783161517679?no_cache=1 order@mohrsiebeck.com

Telefon: +49 (0)7071-923-17

Telefax: $+49(0) 7071-51104$ 